\title{
Identification of Pseudomonas pseudomallei in clinical practice: use of simple screening tests and API 20NE
}

\author{
D A B DANCE, ${ }^{*} \dagger$ V WUTHIEKANUN, ${ }^{*}$ P NAIGOWIT, $\ddagger$ N J WHITE* $\dagger{ }^{*}$ Bangkok Hospital \\ for Tropical Diseases, Faculty of Tropical Medicine, Mahidol University, Thailand, $\dagger$ Tropical Medicine Unit, \\ Nuffield Department of Clinical Medicine, University of Oxford, $\ddagger$ Department of Microbiology, \\ Sappasitprasong Hospital, Ubon Ratchatani, Thailand
}

SUMMARY The API 20NE kit and a simple screening system involving Gram's stain, the oxidase reaction, colistin and gentamicin resistance, and colonial characteristics on a differential agar medium, were used to test 400 strains of Pseudomonas pseudomallei. The API kit identified 390 $(97 \cdot 5 \%)$ strains correctly on first testing and all but one of the remainder on second testing. Only one strain was initially misidentified (as Ps cepacia). The screening system was $100 \%$ accurate in identifying Ps pseudomallei. In non-endemic areas the API $20 \mathrm{NE}$ kit may be used to identify sporadic imported strains of Ps pseudomallei. Such kits may also help to delineate the geographical distribution of melioidosis. In endemic areas the screening tests described offer a cheap, simple, and accurate means of presumptively identifying $P$ s pseudomallei from clinical specimens.

Melioidosis is becoming increasingly recognised as an important medical problem in some areas of south east Asia.' In the United States recrudescent melioidosis is still occasionally seen in veterans of the Vietnam war, ${ }^{2}$ while elsewhere both tourists and immigrants from endemic areas may return with acute or chronic forms of the disease. ${ }^{3}$ The clinical signs of the disease are protean and so diagnosis depends on the isolation and identification of Pseudomonas pseudomallei, the causative organism. Although the bacterium is easy to grow, it is often not recognised by microbiologists in non-endemic areas and may be discarded as a contaminant. This results in delayed diagnosis and treatment, ${ }^{2}$ and may adversely affect the outcome of this potentially lethal infection.

In the past few clinical laboratories were equipped for the detailed identification of oxidase positive, Gram negative rods, but this has changed in recent years with the development of commercial biochemical kits for bacterial identification. We report our experience with one such kit, the API 20NE, and a simple screening system, which we have used to identify Ps pseudomallei in conjunction with clinical studies of melioidosis in north east Thailand. ${ }^{\prime}$

\section{Material and methods}

All tests were performed between August 1986 and

Accepted for publication 12 January 1989
October 1988. Four hundred individual isolates were examined. The origins of these strains were as follows: 10 strains from the United Kingdom National Collection of Type Cultures; 373 clinical isolates from 244 patients in Sappasitprasong Hospital, Ubon Ratchatani, Thailand; one clinical isolate from Bangladesh; ${ }^{4} 16$ clinical isolates from Singapore. The specimens from which the Thai isolates were obtained are shown in table 1.

The first isolate from each patient was identified in the Sappasitprasong hospital laboratory by conventional methods. ${ }^{5}$ Thereafter, isolates from the same patient which had similar colonial characteristics to the original were not formally reidentified.

\section{A PI 20NE TESTS}

API 20NE strips were purchased from API Laboratory Products Ltd, Basingstoke, Hampshire, shipped refrigerated to Thailand, and stored at $4^{\circ} \mathrm{C}$ until use. All equipment and reagents used were manufactured by API except plastic Pasteur pipettes (Alpha Laboratories), oxidase reagent (Difco), and 2 $\mathrm{ml}$ volumes of sterile $0.85 \%$ saline for suspension of organisms (prepared in our laboratory). The manufacturers' instructions were followed precisely for the inoculation and incubation of the strip. The nitrate reduction, indole (TRP) reaction, and glucose fermentation reactions were read after 18-24 hours' incubation. All other results were read at 42-48 hours because it was found that an identification was never 
Table 1 Source of 373 clinical isolates of Ps pseudomallei from north east Thailand

\begin{tabular}{lc}
\hline Type of specimen & No of isolates \\
\hline Blood culture & 157 \\
Pus or wound swabs & 85 \\
Urine & 39 \\
Sputum & 35 \\
Throat swabs & 27 \\
Pleural or pericardial fluid & 8 \\
Peritoneal dialysis or ascitic fluid & 4 \\
Rectal swabs & 7 \\
Cerebrospinal fluid & 4 \\
Bone marrow & 5 \\
Intravenous cannula tip & 2 \\
\hline
\end{tabular}

possible at 24 hours. Results for each test were recorded as positive, negative, or weak; a seven digit profile was ascribed and an identification was obtained by reference to the Analytical Profile Index. For these purposes, a weak reaction was scored as positive.

\section{SCREENING TESTS}

All strains were screened as follows:

1 Gram stain;

2 oxidase test (Spot Test, Difco Laboratories, Detroit, Michigan, USA);

3 subculture on to Columbia agar (Oxoid Ltd, Basingstoke, Hampshire) on to which $10 \mu \mathrm{g}$ gentamicin and $10 \mu \mathrm{g}$ colistin disks (Oxoid) were placed;

4 subculture on to a modification of the medium described by Ashdown ${ }^{6}$ (containing $10 \mathrm{~g}$ tryptic soy broth (Difco), $15 \mathrm{~g}$ agar (Eiken), $40 \mathrm{ml}$ glycerol, $5 \mathrm{ml}$ $0.1 \%$ aqueous crystal violet, $5 \mathrm{ml} 1 \%$ aqueous neutral red and $5 \mathrm{mg}$ gentamicin per litre).
An organism was presumptively identified as $P S$ pseudomallei if: it was an oxidase positive, bipolar, or irregularly staining Gram negative rod, which grew on Columbia agar to within $2 \mathrm{~mm}$ of both antibiotic discs after 24 hours' incubation; had a metallic sheen over the area of confluent growth; had a distinctive sweet, earthy odour; and produced opaque, purple, rugose colonies, with no discolouration of the surrounding medium, after 48-72 hours' incubation on Ashdown's agar.

\section{Results}

\section{API 20NE}

Altogether, 464 API $20 \mathrm{NE}$ tests were performed on the 400 isolates (including 27 tests on colonial variants and 37 repeat tests). The profiles given on the first testing of the commonest colonial form of each isolate are listed in table 2 . In 390 instances $(97.5 \%)$ the profile given suggested that the organism was most likely to be $P S$ pseudomallei. Of the remaining 10 strains, only one gave a profile suggestive of an organism other than $P S$ pseudomallei, and this strain was retested because it seemed to be a typical Ps pseudomallei on the basis of the screening tests. When these 10 strains were tested for a second time, all except one (a strain repeatedly negative for mannitol assimilation) were identified this time as Ps pseudomallei.

The results given in individual tests are shown in table 3. Test results differing from most of the strains were regarded as "false" if they were not repeatable. Colonial variants within a strain usually gave identical profiles and in no instance did they differ by more than one or two of these "false" reactions.

Table 2 API 20NE profiles for 400 strains of Ps pseudomallei

\begin{tabular}{|c|c|c|c|c|c|}
\hline \multirow{2}{*}{$\begin{array}{l}\begin{array}{l}\text { Numerical } \\
\text { profile }\end{array} \\
1156577\end{array}$} & \multicolumn{2}{|c|}{$\begin{array}{l}\text { Analytical profile index identification } \\
\text { (identification percentage) }\end{array}$} & \multirow{2}{*}{$\frac{\text { No of strains }}{254^{*}}$} & \multirow{2}{*}{$\begin{array}{l}\begin{array}{l}\text { No of strains } \\
\text { repeated }\end{array} \\
10\end{array}$} & \multirow{2}{*}{$\begin{array}{l}\begin{array}{l}\text { Numerical profiles on repeat testing } \\
\text { (No of strains) }\end{array} \\
1156577(7)\end{array}$} \\
\hline & Ps pseudomallei & (99.9) & & & \\
\hline $\begin{array}{l}1556577 \\
1156576\end{array}$ & $\begin{array}{l}\text { Ps pseudomallei } \\
\text { Ps pseudomallei }\end{array}$ & $\begin{array}{l}(99.9) \\
(99.9)\end{array}$ & $\begin{array}{l}89 \\
22\end{array}$ & $\begin{array}{l}2 \\
4\end{array}$ & $\begin{array}{l}1156577(2) \\
1156576(3) \\
1156577(1)\end{array}$ \\
\hline $\begin{array}{l}1556576 \\
1156575 \\
1556575 \\
1056577\end{array}$ & $\begin{array}{l}\text { Ps pseudomallei } \\
\text { Ps pseudomallei } \\
\text { Ps pseudomallei } \\
\text { Ps pseudomallei }\end{array}$ & $\begin{array}{l}(99 \cdot 9) \\
(93 \cdot 8) \\
(99 \cdot 5) \\
(81 \cdot 2)\end{array}$ & $\begin{array}{l}7 \\
6 \\
4 \\
3\end{array}$ & $\frac{1}{3}$ & $\begin{array}{l}1156577(1) \\
\overline{1156577(2)} \\
1556577(1)\end{array}$ \\
\hline $\begin{array}{l}1157777 \\
1146577 \\
1156574 \\
1554577 \\
1556557 \\
1156557\end{array}$ & $\begin{array}{l}\text { Not listed } \\
\text { Not listed } \\
\text { Ps pseudomallei } \\
\text { Ps pseudomallei } \\
\text { Ps pseudomallei } \\
\text { Ps pseudomallei } \\
\text { Ps fluorescens }\end{array}$ & $\begin{array}{l}(96 \cdot 5) \\
(97 \cdot 6) \\
(95 \cdot 6) \\
(63) \\
(36 \cdot 9)\end{array}$ & $\begin{array}{l}2 \\
2 \\
2 \\
1 \\
1 \\
1\end{array}$ & $\begin{array}{l}2 \\
2 \\
1 \\
1 \\
1\end{array}$ & $\begin{array}{l}1156577(2) \\
1156577(2) \\
1156577(1) \\
1156577(1) \\
\overline{1556557(1)}\end{array}$ \\
\hline $\begin{array}{l}1456576 \\
1146575 \\
1156567 \\
1557777 \\
1152575 \\
1046577\end{array}$ & $\begin{array}{l}\text { Not listed } \\
\text { Not listed } \\
\text { Not listed } \\
\text { Not listed } \\
\text { Not listed } \\
\text { Ps cepacia }\end{array}$ & $(87 \cdot 1)$ & $\begin{array}{l}1 \\
1 \\
1 \\
1 \\
1 \\
1\end{array}$ & $\begin{array}{l}1 \\
1 \\
1 \\
1 \\
1 \\
1\end{array}$ & $\begin{array}{l}1156577(1) \\
1156577(1) \\
1156577(1) \\
1156577(1) \\
1552577(1) \\
1156577(1)\end{array}$ \\
\hline
\end{tabular}

*Includes 21 strains giving extremely faint opacity in maltose assimilation test, regarded as negative in comparison with other cupules. 
Table 3 Percentage API 20NE test results for 400 strains of Ps pseudomallei

\begin{tabular}{|c|c|c|c|c|}
\hline Test & Positive & Weak & Negative & Notes \\
\hline Nitrate reduction & 100 & - & - & - \\
\hline Indole (TRP) & - & - & 100 & - \\
\hline Glucose fermentation & - & - & 100 & - \\
\hline Arginine dihydrolase & 91 & 8 & 1 & $\begin{array}{l}\text { Negatives were "false" (noted particularly on first } \\
\text { testing after prolonged storage) }\end{array}$ \\
\hline Urease & - & $\overrightarrow{0}$ & 100 & $\overline{0} \quad$. \\
\hline Aesculin hydrolysis & 6 & 20 & 74 & $\begin{array}{l}\text { Most strains appear positive if incubation continued } \\
\text { beyond } 48 \text { hours }\end{array}$ \\
\hline $\begin{array}{l}\text { Gelatinase } \\
\beta \text {-galactosidase }\end{array}$ & $>98$ & $<1$ & 1 & As for arginine dihydrolase \\
\hline $\begin{array}{l}\beta \text {-galactosidase } \\
\text { Assimilation of: }\end{array}$ & - & - & 100 & - \\
\hline Glucose & 100 & - & - & - \\
\hline Arabinose & - & $<1$ & $>99$ & Weak positives were "false" \\
\hline Mannose & $>98$ & 1 & $<1$ & Negative was "false" \\
\hline Mannitol & $>99$ & - & $<1$ & One strain true negative \\
\hline $\mathrm{N}$-acetyl-glucosamine & 100 & - & - & $\overline{50}$ atme \\
\hline Maltose & - & - & 100 & $5 \%$ strains gave very faint opacity, recorded as negative \\
\hline Gluconate & 100 & - & - & $\bar{N}$ \\
\hline Caprate & $>99$ & - & $<1$ & Negative was "false" \\
\hline $\begin{array}{l}\text { Adipate } \\
\text { Malate }\end{array}$ & $>98$ & 1 & $<1$ & One strain true negative \\
\hline Citrate & 79 & 13 & $\overline{8}$ & $\overline{\text { Some strains true negatives }}$ \\
\hline Phenyl-acetate & 84 & 13 & 3 & $\begin{array}{l}\text { Remainder variable, but false negatives particularly if } \\
\text { incubated at }>30^{\circ} \mathrm{C}\end{array}$ \\
\hline Oxidase & 100 & - & - & - \\
\hline
\end{tabular}

\section{SCREENING TESTS}

The predominant colonial types of all 400 strains were correctly identified as $P$ s pseudomallei according to the screening criteria described above. No other organisms isolated from clinical specimens during the study were misidentified as Ps pseudomallei by the screening system. The only bacteria which gave rise to any suspicion were three strains of Ps cepacia, which were gentamicin and colistin resistant and produced coarsely folded colonies on Ashdown's medium. They differed from Ps pseudomallei, however, in lacking bipolarity on Gram staining, causing a brownish discolouration of Ashdown's medium, and producing an odour distinct from that of Ps pseudomallei.

Several strains exhibited considerable colonial variation, particularly after prolonged storage on agar or on direct isolation from sputum. This phenomenon has been long recognised in Ps pseudomallei, and may initially give the impression of a mixed culture. The commonest colonial type seen corresponded to the "rough" type described by Nicholls. ${ }^{7}$ The commonest variant seen resembled the "smooth" type and differed from typical Ps pseudomallei in being non-bipolar and often failing to form wrinkled colonies on Ashdown's medium. Occasionally, frankly mucoid colonies were seen. All such colonial variants were biochemically typical Ps pseudomallei, although they produced stronger alkaline reactions in the arginine dihydrolase test and weaker liquefaction of gelatin than "rough" colonies, both of which are characteristics which have been previously described.' Because they occurred only as minority populations and frequently dissociated to give "typical" colonies on subculture, they are unlikely to cause confusion.
Discussion

We initially undertook these studies because we needed an easily transportable method to confirm the identity of Ps pseudomallei during our clinical studies of melioidosis in north east Thailand. ' The API 20E kit has been reported previously to be appropriate for this purpose ${ }^{8}$ but, in preliminary studies of 34 clinical isolates of Ps pseudomallei from Ubon Ratchatani, we found that the results given by the API $20 \mathrm{E}$ were very difficult to read and resulted in a number of non- or misidentifications (data not shown). The tests for acid production from carbohydrates were particularly troublesome. Thomas also found that the API 20E system only identified $50 \%$ of Ps pseudomallei strains. ${ }^{9}$ In contrast, the API $20 \mathrm{NE}$ has been extremely reliable and has allowed us to identify over $97 \%$ of strains on the first testing and over $99 \%$ on the second. Most of the strains gave the profiles 1156577 or 1556577 , differing only in aesculin hydrolysis. The result of this test seems to be truly variable and depends on the duration of incubation. Repeat testing of strains which initially gave other profiles suggested that the variation was usually due to false or unrepeatable reactions. The only repeatable deviations from the commonest profiles were negative adipate and mannitol assimilations in one strain each, and negative citrate in three of seven strains retested. The API 20NE is thus of little value for biotyping purposes.

The API Analytical Profile Index always records the identification of Ps pseudomallei as "presumptive" and recommends that the organism should be sent to a reference laboratory for confirmatory testing. Other workers have suggested that serological confirmation 
of the identification should be obtained, ${ }^{5}$ although commercial Ps pseudomallei antiserum (Difco) is no longer available. It was not our intention to assess prospectively the specificity of this kit. During the study period, however, specimens from patients with suspected melioidosis grew 22 oxidase positive, Gram negative rods which subsequently proved not to be Ps pseudomallei, but which were tested in the API 20NE system. None of these gave a profile indicative of Ps pseudomallei (data not shown). This suggests that misidentifications are uncommon in this endemic area and serological confirmation is therefore unnecessary. The predictive value of a test is related to the prevalence of the disease, and so misidentification may be more of a problem in areas of low prevalence, where pseudomonads other than Ps pseudomallei comprise most clinical isolates.

Although it is convenient and obviates the need for the production of several conventional biochemical test media with the concomitant problems of quality control, the API $20 \mathrm{NE}$ does not offer any advantages in terms of the speed of identification. We found that the identification was never completed until the second day of incubation. Another disadvantage of the kit is the cost, currently around $£ 2.00$ per organism identified, which may well be beyond the budget of laboratories in those areas where melioidosis is endemic.

In our hands the simple screening system outlined above, although not taxonomically exacting, allowed us to identify Ps pseudomallei with $100 \%$ accuracy. As with the API 20NE system, we have not assessed prospectively the specificity of this simple identification method, but in 27 months of clinical use it has resulted in no misidentifications. It must be emphasised, however, that we have been working in a highly endemic area and are very familiar with the cultural characteristics of $P s$ pseudomallei. Furthermore, as $P$ s pseudomallei is classified as a "category 3" organism in Britain, ${ }^{10}$ it would not be permissible to use the odour of a culture as a primary identifying characteristic, although we have found this to be very useful. Because we routinely use Ashdown's medium for the selective isolation of Ps pseudomallei from clinical specimens, ${ }^{16}$ the performance of these tests has taken little extra time and costs only about $£ 0.10$ per organism. The typical colonial morphology on Ashdown's agar takes at least 48 hours to develop, but the odour and presence of a metallic sheen over confluent growth on Columbia agar, together with appearance on Gram stain, oxidase reaction, and antibiotic sensitivities often permit a presumptive identification at 24 hours.

The API 20NE system should enable any laboratory in non-endemic areas to identify occasional imported strains of Ps pseudomallei. The use of such kits may also help to clarify the true geographical distribution of melioidosis, which may be more widespread than previously appreciated. ${ }^{4}$ In areas where melioidosis is endemic the screening system described above is a simple and economical way of identifying suspected $P S$ pseudomallei strains. In cases of doubt the identification may be confirmed by the API $20 \mathrm{NE}$ system or by conventional tests.

We are grateful to the Director of Sappasitprasong Hospital for his generous support for these studies; to Dr Wipada Chaowagul and the staff of the department of medicine for allowing us access to clinical material from their patients; to Dr Bhinyo Susilavorn, Head of Pathology, Sappasitprasong Hospital; to Ms Nucharee Cholvilai for excellent secretarial assistance; and to Ms Nittaya Teerawattanasook for her invaluable technical help. The NCTC strains of $P s$ pseudomallei were a gift from Dr RG Mitchell, and the strains from Singapore were kindly provided by Dr J Heptonstall and Dr Tan Ai Ling.

This study was funded by the Wellcome Trust of Great Britain as part of the Wellcome-Mahidol University, Oxford Tropical Medicine Research Programme.

\section{References}

1 White NJ, Dance DAB. Clinical and laboratory studies of malaria and melioidosis. Trans $R$ Soc Trop Med Hyg 1988;82:15-20.

2 Morrison RE, Lamb AS, Craig DB, Johnson WM. Melioidosis: a reminder. Am J Med 1988;84:965-7.

3 Bouvy JJ, Degener JE, Stijnen C, Gallee MPW, van der Berg B. Septic melioidosis after a visit to south east Asia. Eur J Clin Microbiol 1987;5:655-6.

4 Struelens M, Mondol G, Bennish M, Dance DAB. Melioidosis in Bangladesh: a case report. Trans R Soc Trop Med Hyg 1988;82: 777-8.

5 Gilardi GL. Pseudomonas. In: Lennette EH, Balows A, Hausler WJ, Shadomy HJ, eds. Manual of clinical microbiology. 4th ed. Washington, DC: American Society for Microbiology, 1985: 350-72.

6 Ashdown LR. An improved screening technique for isolation of Ps pseudomallei from clinical specimens. Pathology 1979;11: 293-7.

7 Nicholls L. Melioidosis, with special reference to the dissociation of Bacillus whitmori. Br J Exp Pathol 1930;11:393-9.

8 Ashdown LR. Identification of Pseudomonas pseudomallei in the clinical laboratory. J Clin Pathol 1979;32:500-4.

9 Thomas AD. Evaluation of the API 20E and Microbact 24E systems in the identification of Ps pseudomallei. Veterinary Microbiology 1983;8:611-5.

10 Advisory Committee for Dangerous Pathogens. Categorisation of pathogens according to hazard and categories of containment. London: HMSO, 1984:6.

Requests for reprints to: Dr D A B Dance, Medical Microbiologist, Hospital for Tropical Diseases, Mahidol University, 420/6 Rajvithi Road, Bangkok 10400, Thailand. 